\title{
A SWOT Analysis of Implementation of Continuous Professional Development for Medical Doctors in Sri Lanka
}

\author{
Samarasinghe, Y.J. ${ }^{1}$, Kumarawansa, W.K.W.S. ${ }^{2}$, Abhayaratne, A.J. ${ }^{3}$, \\ Wickramaratne, I.W.M.J. ${ }^{4}$ \& Wijenayake, P.H. ${ }^{5}$
}

\begin{abstract}
Introduction: Continuous Professional Development (CPD) has been defined as a continuing process, outside formal undergraduate and postgraduate training, that allows individual doctors to maintain and improve standards of medical practice through the development of knowledge, skills, attitudes, and behaviour. However, CPD is not popular for Sri Lankan health professionals. The aim of this article is to conduct a SWOT analysis aiming at the formulation of implementation strategies for CPD for medical doctors in Sri Lanka.
\end{abstract}

Methods: The root causes analysis on CPD was done using Ishikawa diagram aided by the literature. SWOT and TOWS matrix analysis was performed to identify the strengths, weaknesses, opportunities and threats using literature and formulated CPD implementation strategies.

Results: Lack of financial incentives, CPD infrastructure and training programmes by professional colleges, remoteness of doctors from main education centres, lack of time for doctors, CPD being noncompulsory by law have been identified as leading causes against CPD implementation. Availability of considerable fund allocation at Ministry of Health $(\mathrm{MOH})$, good perception towards lifelong learning among doctors as strengths; availability of international jobs for doctors, SLMA initiative to establish island wide CPD, availability of funding agencies and political influence as opportunities were identified to overcome threats and weaknesses.

Conclusion: The $\mathrm{MOH}$ should start a National CPD steering committee with a representation of the SLMC, SLMA, all professional colleges, Medical Faculties, Provincial Directors, Institutional Heads and representation of the Government Medical Officers Association to ensure implementation of compulsory CPD in Sri Lanka.

Key words: Continuous Professional Education, Medical Education, Ministry of Health, Re-validation

\section{Introduction}

Continuing Medical Education (CME) describes continuing education in the field of knowledge and skills of medical practice (Christensen et al., 2015).

\footnotetext{
${ }^{1}$ Registrar in Medical Administration, Postgraduate Institute of Medicine, Sri Lanka.

${ }^{2}$ Regional Director of Health Services, Polonnaruwa, Sri Lanka.

${ }^{3}$ Medical Superintendent, Base Hospital, Meerigama, Sri Lanka.

${ }^{4}$ Director, General Hospital, Trincomalee, Sri Lanka

${ }^{5}$ Director Research, Education and Training Unit, Ministry of Health, Sri Lanka.

Corresponding Author: Dr. Y.J. Samarasinghe

Registrar in Medical Administration, Postgraduate Institute of Medicine, Sri Lanka.

Email: jayanath919@gmail.com
}

It is an episodic intervention designed to address the educational needs of groups of learners and generally teacher centered. It's a lecture based passive learning method often conducted in formal settings such as lecture halls or conference rooms.

CPD should also support specific changes in practice as It is a series of lifelong ongoing self-assessments designed to address the educational needs of individuals which is generally learner centered. Its scope is comprehensive. It encompasses the clinical domain as well as practice management, leadership, administration, education, and an spectrum of professional activities (Filipe et al., 2014) aiming at multi-faceted competencies inherent in medical practice (Christensen et al., 
2015). It owns variety of learning formats such as self-directed active learning, with a rare involvement of supervised training (Christensen et al., 2015) conducted in a variety of different venues including locations other than lecture halls and conference rooms (Filipe et al., 2014). CPD includes all activities that doctors undertake to maintain, update, develop and enhance their knowledge, skills, and attitudes in response to the needs of their patients. Engaging in CPD is a professional obligation and prerequisite for enhancing the quality of health care (WFME, 2019).

The continuous professional life-long learning will maintain professional quality. The term Continuing Medical Education is dealing with knowledge and skills of medical practice, which is still preferred in some countries. The main goal of medical education is the improved health of all people. CPD differs in principles from two formal phases of medical education which are Basic Medical Education and Postgraduate Medical Education. CPD aims to maintain and develop the relevant knowledge, clinical and communication skills and attitudes of doctors, changing according to the needs of patients, developing healthcare delivery system and responding to new challenges arising from the scientific development in medicine and meeting the requirements of licensing bodies and the society (WFME, 2019). Continuing professional education (CPE) fills the need of CPD. It always identifies the needs and negotiating power and interest among multiple stakeholders (Cervero \& Wilson, 2006). Programme development usually starts with an assessment of needs (Caffarella \& Daffron, 2013). Curriculum Development for CPE is a six-step approach that focuses on identifying the problem, needs assessment, establishing goals objectives and educational strategies, implementing and doing an assessment (Kern et al., 2009). Evidence-based medicine is heavily emphasized within the context of CPE in the health and medical professions.

\section{Curriculum Development in the Health and Medical Professions}

The figure 1 describes the factors influencing the CPD curriculum development relevant to the context of United Sates. One's beliefs and assumptions as philosophy and the learning theories are informed to curriculum design of particular context. Evidence Based Medicine, exams like U.S. Medical Licensing Exam (USMLE), Nursing Certification Licensing Exam (NCLEX) and AVP goals (Academic vice presidents of Association of American Medical Colleges) influence the curriculum formulation. This curriculum should deliver an output for learners and to the benefit of the patients whom they serve (Tisdell, 2016).

\section{International CPD standards}

The individual is responsible for identifying CPD needs, planning to address those needs, undertaking CPD activities that are relevant to the practice and support professional development in both the clinical and the nonclinical aspects of practice. Most medical royal colleges and faculties in the United Kingdom have developed CPD schemes to guide and support doctors in maintaining and developing their professional standards in their specialty (GMC, 2012). At the Royal Colleges, Medical professionals have developed tools and templates to enable the doctors to record and reflect on their supporting information for appraisal and revalidation (RCP, 2019). The Royal College Physicians (RCP) have developed tools assisting CPD such as probity report, health report, RCP CPD diary, case review report, untoward incidents report, quality improvement activity report, report of feedback on practice, colleague feedback questionnaires, patient feedback questionnaires, complaints summary report and compliments summary report. Doctors should meet their appraiser before using the college report templates to ensure that they meet local clinical governance requirements are satisfactory to the appraiser (RCP, 2019). The expected attributes of CPD are improvement of knowledge, skills and performance, safety and quality, communication, partnership and teamwork and maintaining trust. The summary of the CPD activities to annual appraisal is an essential requirements for revalidation process at GMC (GMC, 2012). The registration and renewal process of medical practitioner at the Medical Board of Australia (MBA) requires CPD (MBA, 2019). The MBA has recommended different CPD hours for different categories of medical practitioners. The Singapore Medical Council has made CME compulsory for all doctors in Singapore with effect from 1 January 2003 to ensure up-to-date medicine and offering patients good quality of care. Since 1 January 2005 (SMC, 2014), CME was made compulsory for renewal of practicing certificates of doctors(SMC, 2019). The Academy of Medicine, Singapore conducts regular CME and CPD activities for the medical professionals (Academy of Medicine Singapore, 2019). 


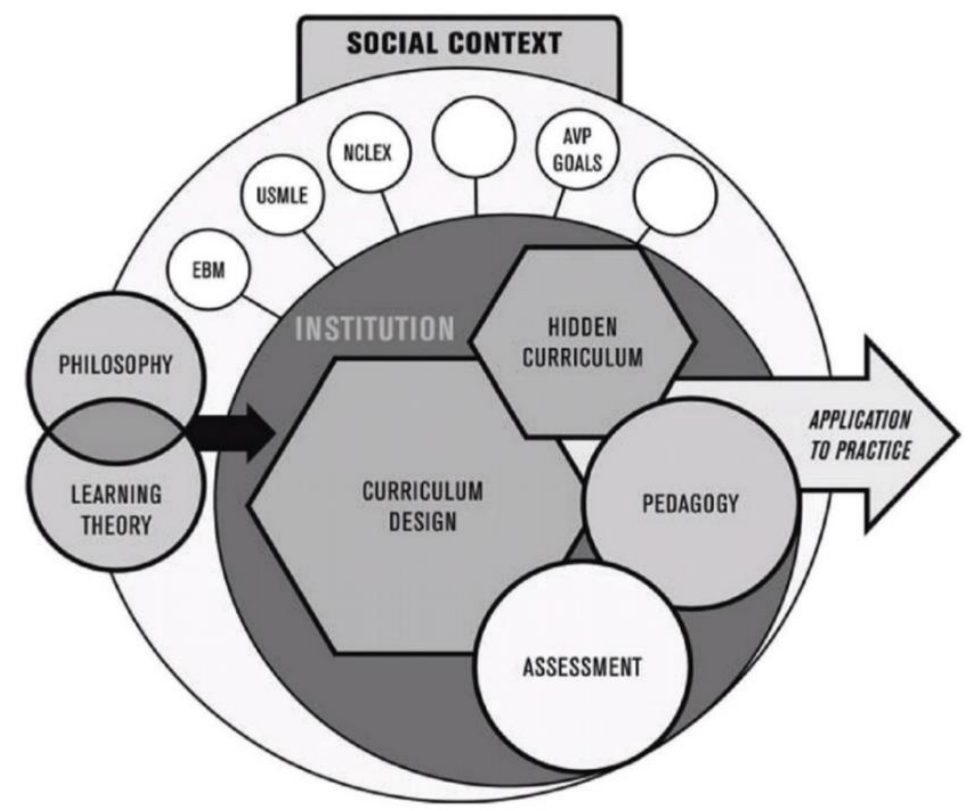

Developing Continuing Professional Education in the Health and Medical Professions through Collaboration; EBM-EvidenceBased Medicine; USMLE- U.S. Medical Licensing Exam; NCLEX-Nursing Certification Licensing Exam; AVP Goals of academic vice presidents of Association of American Medical Colleges (AAMC)

Figure 1: Negotiating Power and Interest for Curriculum Development in the Health and Medical Professions

\section{CME and CPD in Sri Lanka}

In Sri Lanka the concept CME is more popular than CPD. However, CPD remains as the ultimate expectation which gives benefits to patients. There are few institutes conducting CME programmes in Sri Lanka. The Education and Research Unit (ETR) of Ministry of Health $(\mathrm{MOH})$ is the widely functioning government body which conduct CME (ETR, 2019). The Postgraduate Institute of Medicine provides CME such as research methodology programmes for medical professionals in spite of their routine postgraduate training courses (PGIM, 2019). The Sri Lanka Medical Association (SLMA) which is the professional body of all the doctors is conducting a National CPD Certificate (NCPDC) programme for doctors currently (SLMA, 2019). Additionally, the Base hospitals and General hospitals which have consultants in different specialties usually conduct clinical sessions for the doctors as CME activities.

\section{ETR unit of $\mathrm{MOH}$}

The formal government structure established for CME in Sri Lanka is the ETR unit, MOH. The healthcare institutions island wide identify the training gaps of the institutions as Group Inservice Training Programmes (GISTP). Such proposals relevant to all staff categories including doctors are sent to the ETR for approval and fund allocation. The doctors can apply for ETR funds for their individual training programmes conducted by government institutions. Such prior approved training programme fees are reimbursed by the ETR unit, $\mathrm{MOH}$. Thereby $\mathrm{MOH}$ spends an enormous amount of money for improving the knowledge and skills of the medical practice of the professionals and all staff categories by conducting many in service training programmes $(\mathrm{MOH}, 2019)$. During the year 2018 the ETR unit has allocated Rs. 6,807,856 for individual in-service training programmes (ISTP) of doctors. This figure was Rs. $4,394,216$ during 2019. During the year 2018, majority of funds have been allocated for individual ISTP of Directors and Medical superintendents of hospitals ( $n=38,79.5 \%)$. $13.8 \%$ of money had been utilized for individual ISTP of medical officers while $6.5 \%$ was utilized for consultants (Table 1). However, during 2019 , majority of funds have been allocated for individual ISTP of medical officers $(n=21$, $47.5 \%$ ) while $37 \%$ allocated for consultants and registrars $(n=12)$. Only $15.3 \%(n=9)$ of money 
has been allocated for Hospital Directors and medical Superintendents (Table 2). Allocation for individual ISTP by ETR for Senior Lecturers was negligible during 2018 , and there was no allocation during the year 2019 (Tables 1 and 2).

The majority of funds (Rs. 12809297, 26.2\%) of group ISTP have been allocated to training of emergency care of doctors. The fund allocation for other ISTP; productivity, quality, safety, leadership \& management training (Rs. $4363120,8.9 \%)$, infection control \& waste management (Rs. 2623955, 5.3\%), training on communication skills (Rs. 2217230, 4.5\%), training on academic activities and research (Rs. 1377105, 2.8\%), training on NCD prevention (Rs. 1132425, 2.3\%), reproductive health, breast feeding \& nutrition (Rs. 983590 , 2.0\%) (Table 3).

Table 1: Individual ISTP1 Allocations during the year 2018

\begin{tabular}{lccc}
\hline \multicolumn{1}{c}{ Staff Category } & Numbers(n) & $\begin{array}{c}\text { Allocation } \\
\text { LKR }\end{array}$ & \multicolumn{1}{c}{$\%$} \\
\hline Director, Medical Superintendents & 38 & $5,414,150.00$ & 79.5 \\
Consultants and SR & 12 & $447,040.82$ & 6.5 \\
Medical Officers & 28 & $945,165.82$ & 13.8 \\
Senior Lecture & 1 & $1,500.00$ & 0.02 \\
\hline Total & 79 & $6,807,856.64$ & 100 \\
\hline
\end{tabular}

${ }^{1}$ In Service Training programmes. Source: ETR Ministry of Health Sri Lanka

Table 2: Individual ISTP1 Allocations during the year 2019 up to 3rd quarter

\begin{tabular}{lccc}
\hline \multicolumn{1}{c}{ Staff Category } & Numbers & $\begin{array}{c}\text { Allocation } \\
\text { LKR }\end{array}$ & $\%$ \\
\hline Director, Medical Superintendents & 9 & $674,500.00$ & 15.3 \\
Consultants and Registrars & 12 & $1,629,816.32$ & 37.0 \\
Medical Officers & 21 & $2,089,900.00$ & 47.5 \\
Senior Lecturer & 0 & 0.00 & \multicolumn{1}{c}{0} \\
\hline Total & 42 & $4,394,216.32$ & 100 \\
\hline
\end{tabular}

${ }^{1}$ In Service Training programmes. Source: ETR Ministry of Health Sri Lanka

Other Departments of the Health Ministry

There are few other departments that conduct training programmes for healthcare professionals in Sri Lanka. The Family Health Bureau (FHB) usually conducts GISTP on Maternal and Child Health, targeting doctors and other staff categories in different regions of the country (FHB, 2019). The Epidemiology Unit of Ministry of Health (EU) conducts GISTP on communicable diseases (EU, 2019) and the Health Promotion Bureau (HPB) conducts health communication and promotional programmes for doctors island wide (HPB, 2019). 
Table 3: Fund allocation for GISTP1 for Medical officers during 2019

\begin{tabular}{lcc}
\hline \multicolumn{1}{c}{ Programme Category } & $\begin{array}{c}\text { Allocation } \\
\text { LKR }\end{array}$ & \% \\
\hline Productivity, Quality, safety, Leadership \& management Training & 4363120 & 8.9 \\
Training on Academic activities and research & 1377105 & 2.8 \\
Training on Emergency Care & 12809297 & 4.5 \\
training on communication skills & 2217230 & 2.3 \\
Training on NCD prevention & 1132425 & 2.0 \\
Reproductive health, BF \& Nutrition & 983590 & 3.6 \\
Mental Health training programmes & 1787565 & 5.3 \\
Infection control \& Waste Management & 2623955 & 44.1 \\
Other 2 training programmes & 21548085 & 100 \\
\hline Total & 48842372 & \\
\hline
\end{tabular}

${ }^{1}$ Group In Service Training Programmes; ${ }^{2}$ This includes Clinical sessions, Computer training, Training of trainer programmes, Cosmetic training programmes, Donor training for transplants, Palliative care, Gender base violence, Good inter programmes, post op care training etc.: Source: ETR Ministry of Health Sri Lanka.

\section{Sri Lanka Medical Association (SLMA)}

The SLMA is the oldest professional medical association in Asia with a history that dates back to 1887 and is the national professional medical association in Sri Lanka. This brings all medical practitioners of all grades and all branches of medicine together (SLMA, 2019). The SLMA provides opportunities for continuous professional development for doctors and allied health professionals. The SLMA has initiated the National Continuing Professional Development Certificate (NCPDC) to Sri Lankan doctors to ensure highest professional standards among doctors.

This is not a compulsory programme for revalidation of registration of medical professionals linking to Sri Lanka Medical Council (SLMC). Its objective is to ensure good professional practice for patients. This gives additional advantages such as for those aspiring for jobs or training posts abroad, recognition by other professional bodies overseas, protection against litigation when the skills or knowledge of doctors are challenged in a court of law. This programme is fully funded by the $\mathrm{MOH}$. There are many CPD activities linked to NCPDC such as participation academic sessions of a professional colleges or associations, regional meetings, local meetings, case conferences, non-routine teaching, journal club activities, participation at skills training workshops or any other skills related activities, research and publications, reading on a topic or article and writing a summary, reflective learning etc. (NCPDC information and guidance book, 2010).

\section{Method}

The root causes have been identified for absence of compulsory CPD for doctors using the problem analysis technique using an Ishikawa diagram (Figure 2). Literature search related to global as well as the local setting was conducted to assist the problem analysis process. A SWOT analysis and TOWS matrix analysis for strategy a formulation were performed (Oxford college of marketing, 2020) to identify the strengths, weaknesses, opportunities and threats and to formulated strategies to implement of CPD in Sri Lanka. 


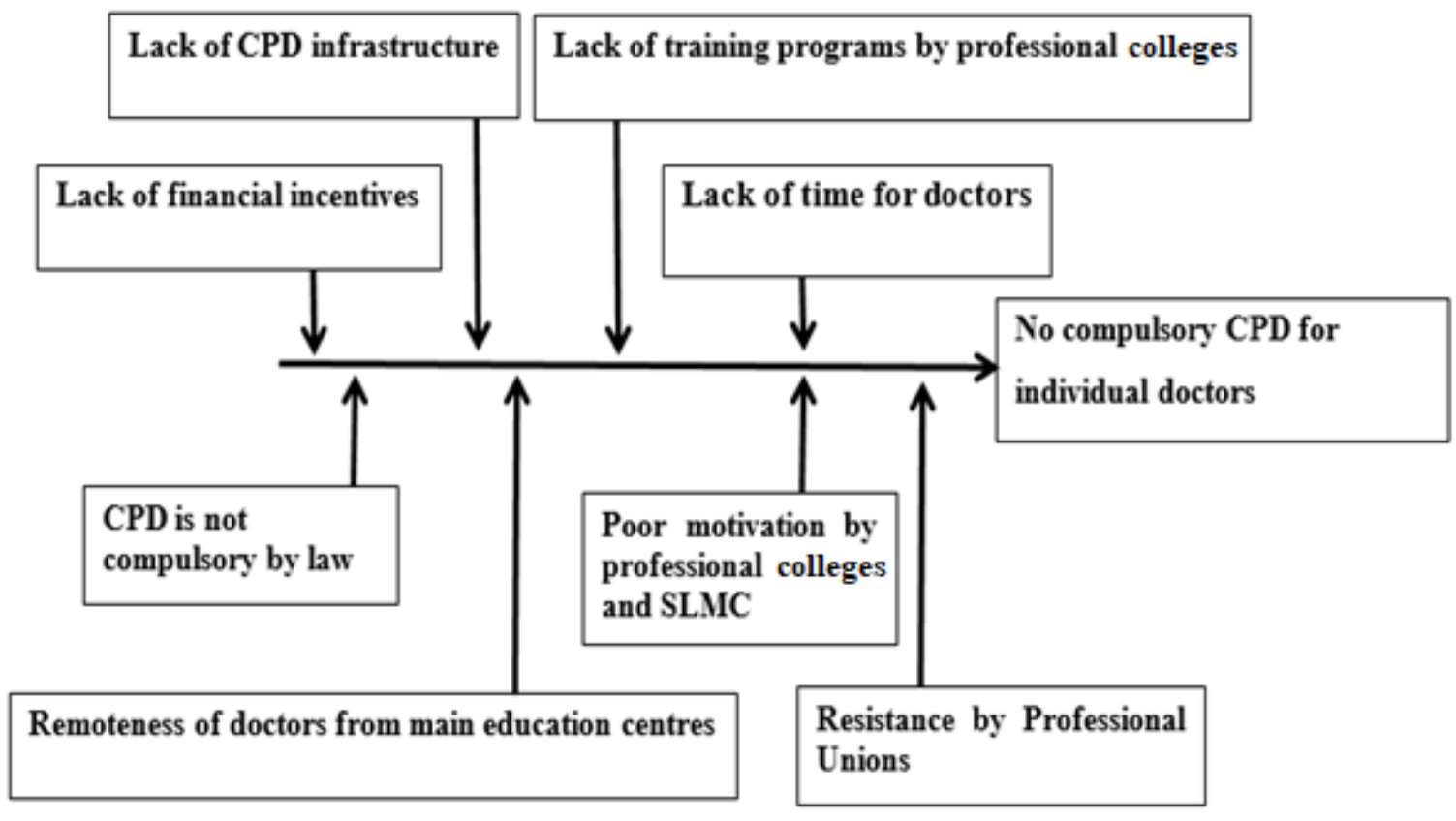

Figure 2: Ishikawa diagram of problem analysis

\section{Results}

In Sri Lanka, a handfull of doctors are currently engaged in CPD. Few attempts of implementing CPD has been unsuccessful due to few faults in the system. The main reason behind non-engagement in CPD is that SLMC revalidation doesn't need CPD updates of doctors in the current context (SLMA, 2019). There are few leading factors identified at situational analysis that influence a compulsory CPD system in Sri Lanka.

\section{Lack of financial incentives}

In UK, doctors are granted financial incentives to archive CPD goals in their practice. In UK, a $£ 500$ the CPD allowance is paid for a GP trainer for 2019/2020 financial year (Health Education England, 2019). Research findings revealed that underfunding is a barrier against CPD programmes (Davis \& Parboosingh, 1993). When the figures are attributed to the Sri Lankan context, it is about 2500 Million rupees worth money for all the doctors of 25600 . However, allocation of such financial incentives are a problem in Sri Lankan context because current health allocation remains at a low percentage (Epa, 2003). In 2016, expenditure on health for Sri Lanka was 3,184 million US dollars which is $3.9 \%$ of the total GDP (World Data Atlas, 2019) but this figure has become $3.5 \%$ in 2019. Therefore it's challenging of increasing further allocation on financing.

\section{Lack of CPD infrastructure}

Sri Lanka lacks the infrastructure and mechanism to offer appraisal and CPD for doctors (Epa, 2003). There is a need of such infrastructure at institutional level and provincial level in order to ensure a feasible platform for doctors for their CPD activities such as national level, provincial and institutional level CPD committees, clinical societies (Jayarathne et al., 2016) and appraisal system for CPD for doctors (Epa, 2003).

\section{Remoteness of doctors from main education centres}

In NHS Scotland, research evidence shows that a significant proportion of doctors have increased perceptions of remoteness from main education centres as a barrier for CPD (Ikenwilo \& Skåtun, 2014). In the Sri Lankan context, most doctors usually have to work in a rural setting during early years of their career. Junior consultants also need to start from remote areas once initially appointed. 
Lack of time for doctors

Glazebrook and Harrison revealed in a study of rural remote medical practitioners that lack of time is the most identified barrier to CPD (Glazebrook \& Harrison, 2006). Similarly, Price et al., revealed that the most frequently reported barrier to implement CPD among a group of health care professionals in Colorado, was lack of time (Price et al., 2010). Time factor and work load have been identified as barriers by many researchers (Davis \& Parboosingh, 1993). In the Sri Lankan setting the government medical officers engage in private practice in their off-duty hours and provide the bulk of private primary outpatient care (Rannan-Eliya et al., 2015). Hence the time factor is one of the major barriers against CPD in Sri Lanka.

\section{Lack of training programmes by Professional colleges}

Adequate CPD training programmes are not conducted by professional colleges. Aditionally, academic disciplines have not been introduced for continuous quality improvement for the undergraduate curriculum (Epa, 2003).

\section{$C P D$ is not compulsory by law}

The CPD standards and policies are regulated either by the Ministry of Health or Medical Councils in countries such as UK, Australia, New Zealand and Singapore. However, policies in terms of CPD of doctors in Sri Lanka are not yet developed (Jayarathne, 2016). The SLMC has proposed legal amendments to medical ordinance during 2003 (Epa, 2003).

\section{TOWS Matrix to identify strategies to implement CPD by MOH Sri Lanka}

According to the SLMC there are 25600 registered doctors approximately (SLMC, 2019). In 2006, De Silva et al, revealed that 70 percent of active registrants are employed in the Health Ministry, 3 percent in the universities, 12 percent in the private sector and the remaining 15 percent are overseas (De Silva et al., 2008). Therefore Ministry of health Sri Lanka is the largest institution which occupies biggest portion of medical doctors. Analysing its strengths and weaknesses will enable to formulate the strategies to establish alternative solutions to implement CPD system in health system.

\section{Strengths(S)}

1. Most of the funds allocated annually to ETR of $\mathrm{MOH}$ is returned at the end of the year usually. The DGHS is in an agreement to find financial allocations (Epa, 2003). The appropriation bill and budget proposals for 2019 has an allocation of Rs. 232.7 billion for the health sector which is about $3.5 \%$ of the total GDP. This includes Rs. 182 billion recurrent expenditure and Rs. 50.7 billion of capital expenditure. Out of that only a 936.5 million rupees have been allocated for all the training programmes of the Ministry of Health. But only 53.1 Million rupees have been allocated for training of doctors during 2019 (Table 2 and 3 ).

2. The MOH has the ETR an established body governed under a Deputy Director General is itself a strength (ETR Unit, 2019).

3. Research evidence in "Grade Medical Officers perception towards lifelong learning" by Jayaratne et al., revealed that a majority of government medical officers (98\%) perceived CPD as a requirement (Jayarathne, 2019).

\section{Weaknesses (W)}

1. Resistance of doctors against their quality assurance is found in all countries with healthcare systems. A research finding showed that, only around $50 \%$ were willing to undertake mandatory CPD (Jayarathne, 2019). Other factor for doctor's resistance is lack of understanding about quality improvement.

2. Sri Lanka has lack of infrastructure and mechanism to offer appraisal and CPD for doctors (Epa, 2003) which creates wasting of time and remoteness working difficulties of doctors.

3. Currently Sri Lanka is lacking a policy to recognize the needs of CPD $(\mathrm{MOH}, 2019)$

4. $\mathrm{MOH}$ has no policy on updated system of performance evaluation for medical professionals $(\mathrm{MOH}, 2019)$.

\section{Opportunities (O)}

1. The revalidation will enable doctors to get international job opportunities (NCPDC information and guidance book, 2010). 
2. SLMA has taken an initiative with other professional colleges to establish island wide CPD programme for doctors (Epa, 2003). The NCPDC is the only programme run by the SLMA at current context (NCPDC information and guidance book, 2010).

3. There are donor funding agencies such as WHO and Asian development bank which are currently funding for health system strengthening such as primary healthcare strengthening projects (ADB, 2019).

4. The current political system can be utilized as an opportunity for system strengthening as the health sector is a critical factor concerning to people's wellbeing.

\section{Threats $(T)$}

1. The government finds it difficult to allocate financial incentives which are a problem in Sri Lankan context under current budgetary constraints.

2. The professional colleges and academic disciplines are lacking training programmes for CPD (Epa, 2003). The UK, Australia, New Zealand and Singapore were able to update their CPD standards and policies which are regulated either by the Ministry of Health or Medical Councils (GMC, 2012; MBA, 2014; MCNZ, 2014; SMC, 2014). However SLMC which is the statutory body is yet to develop policies and update the medical ordinance to support CPD of doctors in Sri Lanka. CPD not being mandatory by law is identified as a major weakness against CPD in Sri Lanka.

"Maxi-Maxi" Strategy (SO)

Strategies that use strengths to maximize opportunities

The $\mathrm{MOH}$ can accommodate contract basis foreign job opportunities for doctors having NCPDC issued by SLMA. Thereby $\mathrm{MOH}$ can popularize the need of CPD among doctors.

$\mathrm{MOH}$ ETR unit funds better utilized for advocacy programmes with professional bodies to initiate CPD activities and sustain CPD committee activities to legalize CPD as a priority factor.
"Maxi-Mini" Strategy (ST)

Strategies that use strengths to minimize threats

In 2019, 48.8 Million rupees have been allocated for GISTP and 4.3 Million rupees have been allocated for individual training programmes. However Dolmans and Schmidt revealed that, problem based learning is a method of interactive and more effective learning than traditional methods in terms learning skills (Dolmans \& Schmidt, 1996). Another Cochrane study by Davis, et al., shows that interactive CME activities show evidence of improving the performance while traditional didactic lectures don't do so (Davis et al., 1999). Going by these research evidence the fund allocation used for individual and group inservice training programmes can be effectively utilized for CPD programmes of doctors. However out of 936.5 million rupees allocated for education and training, a reasonable bulk money should be allocated for doctors CPD as it has much more impact on health system in long run.

Necessary arrangements should be planned to better utilized Ministry funds to start and promote of CPD activities of professional colleges. The $\mathrm{MOH}$ should do sustainable advocacy programmes to SLMC to initiate necessary amendments to medical ordinance to support compulsory CPD for the revalidation process.

"Mini-Maxi" Strategy (WO)

Minimize weaknesses by taking advantage of opportunities

The $\mathrm{MOH}$ should intervene to get foreign job opportunities through CPD schemes for doctors by negotiating with foreign governments. The resistance of doctors for CPD can be minimized by such job opportunities.

Jayaratne et al., point out that Sri Lanka need a good system for CPD establishment. It consists a system of SLMC as overall policy maker, $\mathrm{MOH}$ as the governing body, a national level CPD Committee which is the CPD planner at national level, provincial level CPD Committee which is the regulatory body from national level to provincial level and between different clinical societies and institutional level CPD Committees (Jayarathne, 2016). 
One of the major weaknesses of $\mathrm{MOH}$ is lacking the infrastructure for CPD in provincial and institutional levels. Donor agencies like $\mathrm{ADB}$ and $\mathrm{WHO}$ can be utilized for strengthening the relevant infrastructure for this purpose.

The need of politicians for system strengthening, can be better utilized to overcome internal weaknesses such as infrastructure strengthening at provincial and institutional level to ensure good CPD programme.

The SLMA and the assistance of professional colleges can be obtained to introduce NCPDC programme at provincial set up to overcome the resistance of doctors through better awareness.

\section{"Mini-Mini" Strategy (WT)}

Strategies that minimize weaknesses and avoid threats

More advocacy must be conducted for academic disciplines such as medical faculties and professional colleges to introduce continuous quality improvement programmes for undergraduate curriculum to overcome resistance and more awareness of professional quality improvement of doctors.

The MOH should do advocacy to politicians to get their support for necessary amendments to medical ordinance to make CPD compulsory. Steps must be taken by DDG ETR to formulate a good policy of updated performance appraisal of medical doctors working in $\mathrm{MOH}$.

A professional committee lead by $\mathrm{MOH}$ convening all professionals including union members should meet up regularly to solve barriers of CPD. The positive attitudes of most of doctors for CPD will help to overcome barriers against it. More and more awareness of union members and doctors will help to overcome their resistance against CPD.

\section{Conclusion and Recommendations}

There are few leading causes identified for failure of compulsory CPD programme such as lack of financial incentives, lack of CPD infrastructure, remoteness of doctors from main education centres, lack of time for doctors, lack of training programmes by professional colleges and CPD being non-compulsory by the law. The $\mathrm{MOH}$ should take a lead to of staring CPD as approximately $70 \%$ of doctors are occupied by them. The $\mathrm{MOH}$ should start a
National CPD steering committee with a representation of SLMC, SLMA, all professional colleges, Medical faculties, Provincial directors, institutional heads and representation of government medical officers association. An agenda must be prepared to address most important issues such as establishing CPD infrastructure at provincial and institutional levels, starting CPD training programmes in professional colleges and institutional levels create necessary amendments in medical ordinance, provision of financial incentives for the doctors.

\section{References}

Asian Development Bank (2019) Available at: https://www.adb.org/news/adb-provides-50million-enhance-sri-lankas-health-system.

Caffarella, R., \& Daffron, S. (2013). Planning Programmes for Adult Learners. San Francisco, CA: Jossey-Bass.

Cervero, R., \& Wilson, A. (2006). Working the Planning Table. San Francisco, CA: JosseyBass.

Christensen, J., Grant, J., Karle,H., Lindgren, S., Nystrup, J. and Sjöström, H. (2015). Continuing Professional Development of Medical Doctors. World Federation for Medical Education Global Standards for Quality Improvement. The 2015 Revision. WFME Office University of Copenhagen Denmark.

Continuing Medical Education for Doctors. Singapore Medical Council 2019). Available at: https://www.healthprofessionals.gov.sg/smc/cont inuing-medical-education-(cme)-for-doctors.

Continuing Professional Development. Academy of Medicine Singapore (2019). Available at: https://www.ams.edu.sg/about-us/overview.

Continuing Professional Development. Registration standard (2016). Medical Board of Australia. Available at: https://www.medicalboard.gov.au.

Davis, D., O'Brien, M. A., Freemantle, N., Fredric, M., Mazmanian, P., \& Taylor-Vaisey, A. (1999). Impact of Formal Continuing Medical Education. The Journal of the American Medical Association, 282, 9, pp. 867-874.

Davis, D.A.V.E. \& Parboosingh, J. (1993) "Academic" CME and the Social Contract. Academic Medicine, 68, 5, pp. 329-32.

De Silva, N., Perera, K., Gunatunge, R. \& Tantrigoda, D. (2008). How Many Doctors Should Sri Lanka Have? Ceylon Medical Journal, 53, 3, pp. 93-98. 
Dolmans, D., \& Schmidt, H. (1996). The advantages of problem-based curricula. Postgraduate Medical Journal, 72, 851, pp. 535-538.

Epa, S.S. (2010) National CPD certificate: Information and Guidance Book. Colombo: Sri Lanka Medical Association.

Epidermiology Unit (EU). (2019). Ministry of Health Sri Lanka. Available at: http://www.epid.gov.lk/web/index.php?lang=en

ETR Unit (2019). Ministry of Health Sri Lanka.

Family Health Bureau (FHB). (2019). Available at: https://www.fhb.health.gov.lk/index.php/en/comp onent/search/?searchword=Training\&searchphr ase $=$ all \&ltemid $=502$.

Filipe, H.P., Silva, E.D., Stulting, A.A. \& Golnik, K.C. (2014) Continuing Professional Development: Best practices. Middle East African Journal of Ophthalmology, 21, 2, p. 134.

General Medical Council (GMC). (2012).

Glazebrook, R.M. \& Harrison, S.L. (2006) Obstacles and Solutions to Maintenance of Advanced Procedural Skills for Rural and Remote Medical Practitioners in Australia. Rural Remote Health 2006; 6: pp. 1-14.

Health Education England. (2019). NHS. Available at: https://www.westmidlandsdeanery.nhs.uk/GP/G P-Practice-Payments

Health Promotion Burearu (HPB). (2019). Ministry of Health Sri Lanka. Available at: http://hpb.health.gov.lk/web/index.php/en/home

Ikenwilo, D. \& Skåtun, D. (2014) Perceived Need and Barriers to Continuing Professional Development among Doctors. Health Policy, 117, 2, pp. 195202.

Jayarathne, Y.G.S.W., Karunathilake, I.M. \& Marambe, K.N. (2016) Development of Continuing Professional Development (CPD) Provision Framework for Sri Lankan Grade Medical Officers. South East Asian Journal of Medical Education, 10, 1, pp. 27.

Thomas, P.A., Kern, D.E., Hughes, M.T. \& Chen, B.Y. eds. (2016) Curriculum Development for Medical Education: a Six-step Approach. JHU Press.

Medical Board Australia (MBA). (2014) \& (2019).

Medical Council New Zealand (MCNZ). (2014) \& (2019).
Ministry of Health (MOH) Sri Lanka (2019).

Ministry of Finance Sri Lanka (2019) Available at:http://www.treasury.gov.Ik/documents/10181/ 490927/V_01_Approved_E.pdf/378d791a-3c6848d8-8648-7cde311d3b9̄9.

Oxford College of Marketing. (2020). TOWS Analysis: Step by Step Analysis. Available at: https://blog.oxfordcollegeofmarketing.com/2016/ 06/07/tows-analysis-guide/ Access date: 07.03.2020.

Postgraduate Institute of Medicine (PGIM). (2019). University of Colombo. Sri Lanka. Available at: https://pgim.cmb.ac.lk.

Price, D.W., Miller, E.K., Rahm, A.K., Brace, N.E. \& Larson, R.S. (2010) Assessment of Barriers to Changing Practice as CME Outcomes. Journal of Continuing Education in the Health Professions, 30, 4, pp. 237-245.

Principles of Continuing Professional Development. (2012). General Medical Council (GMC), UK. Available at: https://www.gmc-uk.org//media/documents/cpd-guidance-for-all-doctors0316_pdf-56438625.pdf.

Rannan-Eliya, R.P., Wijemanne, N., Liyanage, I.K., Jayanthan, J., Dalpatadu, S., Amarasinghe, S. \& Anuranga, C. (2015) The quality of outpatient primary care in public and private sectors in Sri Lanka-how well do patient perceptions match reality and what are the implications?. Health policy and planning, 30, suppl_1, pp. i59-i74.

Royal College of Physicians (RCP) (2019) Supporting information for appraisal and revalidation: guidance for physicians Based on the Academy of Medical Royal Colleges and Faculties' core guidance for all doctors Second Edition. Available at: https://www.rcplondon.ac.uk/educationpractice/advice/guidance-physicians-supportinginformation-appraisal-and-revalidation.

Seneviratne, S.D.A. (2003) Revalidation of Sri Lankan doctors. Journal of the College of Community Physicians of Sri Lanka, 8, 1.

Singapore Medical Council (SMC) (2014).

Sri Lanka Medical Association (SLMA). (2019). Available at: https://sIma.lk

Sri Lanka Medical Council (SLMC). (2019).

Tisdell, E. L. (2016) 'Developing Continuing Professional Education in the Health and Medical Professions Through Collaboration: Developing.' (August 2017), pp. 68-79. 
World Data Atlas, (2019). Available at: https://knoema.com/atlas/Sri

Lanka/topics/Health/Health-

Expenditure/Expenditure-on-health. at:

\section{(2019)}

Available

https://wfme.org/standards/cpd. at: 